\title{
Learning Valuable Perspectives on Improving the World's Health Through the Post-2015 Development Agenda: A Response to Recent Commentaries
}

Agnes Binagwaho ${ }^{1,2,3,4^{*}}$, Kirstin Woody $\operatorname{Scott}^{2}$

\author{
*Correspondence to: Agnes Binagwaho, Email: agnes_binagwaho@hms.harvard. \\ edu \\ Copyright: $\odot 2016$ by Kerman University of Medical Sciences \\ Citation: Binagwaho A, Scott KW. Learning valuable perspectives on improving \\ the world's health through the post-2015 development agenda: a response to \\ recent commentaries. Int J Health Policy Manag. 2016;5(4):289-290. doi:10.15171/ \\ ijhpm.2016.04 \\ Received: 2 January 2016, Accepted: 12 January 2016, ePublished: 19 January 2016
} $s$ the world has transitioned from the Millennium Development Goals (MDGs) to the Sustainable Development Goals (SDGs), we have been pleased to observe thoughtful and constructive dialogue among policy-makers, academics, stakeholders, activists, and many others regarding these global policies aimed at improving the health and well-being of the world now and in the future. Such reflections were present in the four comments that we had the pleasure of reviewing in response to our IJHPM perspective titled "Improving the World's Health Through the Post-2015 Development Agenda: Perspectives from Rwanda." We appreciate the opportunity to respond to them here. First, Armah expanded upon the principles we summarized for Rwanda to showcase the vital challenges that African nations will continue to struggle with in the post-MDG era. We appreciate the crux of Armah's argument that "addressing inequalities and promoting more integrated approaches to health service delivery is vital for consolidating and sustaining the health sector achievements in Africa." 2 Rwanda's progress over the past two decades offers a testament to the value of this integrated approach, not only across various Ministries in the public sector, but also through public-private partnerships. Indeed, in a complementary comment, Alleyne made an important distinction between multisectoral and intersectoral collaboration in relation to our paper. ${ }^{3}$ Both forms of collaboration have had a tremendous impact on Rwanda's progress in improving the lives of its people. ${ }^{1,45}$ Further, Alleyne shared constructive views on the importance of leadership in health and the importance of being mindful of health system strengthening as a needed goal. As Alleyne rightfully pointed out, we did not explicitly note health system strengthening as one of the principles for Rwanda's progress. In many ways, each principle within our manuscript inherently assumed the importance of ensuring efforts that simultaneously strengthened Rwanda's health system, but we fully value the importance of explicitly acknowledging this principle on its own. It is also important to note, however, that Rwanda's collective progress as a nation in terms of improving healthcare indicators has required not simply strengthening of the health system, but the strengthening of an entire national vision for a better and healthier tomorrow; a vision that promotes social protection while embedding health system strengthening in the entire development of the country. ${ }^{6}$ If Rwanda had only focused on strengthening its healthcare delivery system while ignoring fault lines in education, transportation, business and so forth, it would not have been possible to make the gains that Rwanda has witnessed over the past two decades. ${ }^{4}$ This is why the concept of the "Social Cluster," which we note in our article and elsewhere, may be of interest to leaders elsewhere who are revisiting how to operationalize their plans to meet the targets set forth by the Global Goals. ${ }^{1,7}$ Further, this aligns well with Alleyne's emphasis on the importance of leadership, vision and governance in this process.

Third, Yamey and colleagues ${ }^{8}$ provided a thoughtful analysis in response to the five principles we offered in our manuscript as being important to Rwanda's progress to date, which they aptly summarized as: (1) the importance of equity, (2) quality health services, (3) evidence-informed policy, (4) intersectoral collaboration, and (5) effective collaboration between countries and multilateral agencies. Creatively, Yamey et al illustrated how each of these principles were visible in the landmark Lancet Commission report published in 2013: "Global Health 2035: A World Converging within a Generation." Yamey and colleagues explain how implementing these principles has helped Rwanda move from a country, which was once considered a "lost cause" to one that can now be described as a "country that copes" and thus working towards the global goal of "Convergence." 8,9

Lastly, $\mathrm{Xu}$ et $\mathrm{al}^{10}$ provide a comment that expands upon our perspective by offering lessons from three health reform strategies from Asia. Xu and colleagues described how the 5 principles we described as integral to Rwanda's progress translate into the experience of Asian healthcare systems, including the successes and challenges of Taiwan's National Health Insurance to China's payment reforms. Specifically, the countries' health reforms for universal health coverage (UHC) are described as an integrated and inclusive solution to advance the global health development agenda. Further, we share $\mathrm{Xu}$ and colleagues' enthusiasm for leveraging advances in information technology and "seizing the opportunity" to have it improve evidence-based policy-making. ${ }^{10}$

A common thread in our perspective and each of these four helpful responding commentaries includes a commitment to equity and meaningful strengthening of health systems. We share in the motivation to build upon lessons learned through the MDGs and work collectively and effectively together as we

Full list of authors' affiliations is available at the end of the article. 
now live in the SDG era. With the impressive array of leaders who shared their valuable perspectives on this article, we can only be further optimistic about not only the dialogue, but also the action that we can collectively take to improve health for all in the SDG era and beyond.

\section{Ethical issues}

Not applicable.

\section{Competing interests}

Authors declare that they have no competing interests.

\section{Authors' contributions}

Both authors contributed equally to the development and revision of this paper.

\section{Authors' affiliations}

${ }^{1}$ Minister of Health, Kigali, Rwanda. ${ }^{2}$ Harvard Medical School, Boston, MA, USA. ${ }^{3}$ Geisel School of Medicine, Dartmouth University, Hanover, NH, USA. ${ }^{4}$ University of Global Health Equity, Kigali, Rwanda.

\section{References}

1. Binagwaho A, Scott KW. Improving the world's health through the post-2015 development agenda: perspectives from Rwanda. Int J Health Policy Manag. 2015;4(4):203-205. doi:10.15171/ ijhpm.2015.46

2. Armah BK. Sustaining health for wealth: perspectives for the post-2015 agenda; Comment on "Improving the world's health through the post-2015 development agenda: perspectives from Rwanda." Int J Health Policy Manag. 2015;4(10):673-675. doi: 10.15171/ijhpm.2015.112
3. Alleyne G. Lessons and leadership in health; Comment on "Improving the world's health through the post-2015 development agenda: perspectives from Rwanda." Int J Health Policy Manag. 2015;4(8):553-555. doi:10.15171/ijhpm.2015.107

4. Binagwaho A, Farmer PE, Nsanzimana S, et al. Rwanda 20 years on: investing in life. Lancet. 2014;384(9940):371-375. doi:10.1016/S0140-6736(14)60574-2

5. Nuwagaba A. Public private partnerships (ppps) and their effect on services delivery in Rwanda. International Journal of Economics, Finance and Management. 2013;2(5):356-359.

6. Government of Rwanda. Economic Development and Poverty Reduction Strategy (EDPRS2). http://www.edprs.rw/content/ edprs-2. Cited January 4, 2015. Published 2013.

7. Binagwaho A. Preparation Is Paramount. Finance \& Development. 2014:51(4):33.

8. Yamey G, Fewer S, Beyeler N. Achieving a "grand convergence" in global health by 2035: Rwanda shows the way; Comment on "Improving the world's health through the post-2015 development agenda: perspectives from Rwanda." Int J Health Policy Manag. 2015;4(11):789-791. doi:10.15171/ijhpm.2015.143

9. Jamison DT, Summers LH, Alleyne G, et al. Global health 2035: a world converging within a generation. Lancet. 2013;382(9908):1898-1955. doi:10.1016/s0140-6736(13)621054

10. Xu Y, Huang C, Colón-Ramos U. Moving toward universal health coverage (UHC) to achieve inclusive and sustainable health development: three essential strategies drawn from Asian experience; Comment on "Improving the world's health through the post-2015 development agenda: perspectives from Rwanda." Int J Health Policy Manag. 2015;4(12):869-872. doi:10.15171/ ijhpm.2015.156 